\title{
THE SPRING MEETING IN BERKELEY
}

The three hundred thirty-second meeting of the American Mathematical Society was held at the University of California on Saturday, April 11, 1936, Professor H. F. Blichfeldt presiding.

The attendance included the following twenty-seven members of the Society:

H. C. Ayres, H. M. Bacon, E. T. Bell, B. A. Bernstein, H. F. Blichfeldt, F. A. Butter, G. C. Evans, A. L. Foster, E. C. Goldsworthy, O. G. Harrold, Frank Irwin, R. D. James, D. N. Lehmer, S. H. Levy, J. C. C. McKinsey, C. B. Morrey, F. R. Morris, H. P. Robertson, Alvin Sugar, L. H. Swinford, J. M. Thompson, V. H. Tingey, J. V. Uspensky, Morgan Ward, A. R. Williams, B. C. Wong, H. S. Zuckerman.

Luncheon for members and their guests was served at the Faculty Club.

Titles of papers read at the meeting follow. Those whose abstract numbers are followed by the letter $t$ were read by title. Mr. Webb was introduced by Professor Bell; Messrs. Highberg, Paxson, Mersman, Taylor, and Elconin by Professor Michal.

1. Postulates for abelian groups and fields in terms of nonassociative operations, by Professor B. A. Bernstein. (Abstract No. 42-5-133.)

2. On Boolean functions of $n$ variables, by Mr. J. C. C. McKinsey. (Abstract No. 42-5-134.)

3. Sets on which a harmonic function becomes positively infinite, by Professor G. C. Evans. (Abstract No. 42-5-135.)

4. Pseudo-polynomials in abstract spaces, by Mr. I. E. Highberg. (Abstract No. 42-5-136.)

5. The differential in abstract linear spaces with a topology. II, by Professor A. D. Michal and Mr. E. W. Paxson. (Abstract No. 42-5-137.)

6. Note on formulas for the number of representations of an integer as a sum of $2 h$ squares, by Dr. R. D. James. (Abstract No. 42-5-138.)

7. A new summation method for divergent series, by Mr. W. A. Mersman. (Abstract No. 42-5-139.) 
8. Note on an inversion formula, by Professor E. T. Bell. (Abstract No. 42-5-140.)

9. On the solutions of quasi-linear elliptic partial differential equations, by Professor C. B. Morrey, Jr. (Abstract No. 42-5141.)

10. The elementary analysis of the calculus of sequences, by Professor Morgan Ward. (Abstract No. 42-5-142.)

11. Development of the algebra of n-valued logic, by Mr. D. L. Webb. (Abstract No. 42-5-143.)

12. On a problem by John III Bernoulli, by Professor J. V. Uspensky. (Abstract No. 42-5-144-t).

13. Existence theorem on implicit vector functions, by Dr. I. M. Hostetter. (Abstract No. 42-5-145-t.)

14. Abstract euclidean spaces. IV, by Professor A. D. Michal, Mr. I. E. Highberg, and Mr. A. E. Taylor. (Abstract No. 42-5-146-t.)

15. Analytic functions in general analysis. II, by Mr. A. E. Taylor. (Abstract No. 42-5-147-t.)

16. An existence theorem for divergent series, by Mr. W. A. Mersman. (Abstract No. 42-5-148-t.)

17. Differential properties of abstract transformation groups with abstract parameters. II, by Professor A. D. Michal and Mr. Victor Elconin. (Abstract No. 42-5-149-t.)

18. General tensor analysis, by Professor A. D. Michal. (Abstract No. 42-5-150-t.)

In the absence of Associate Secretary T. M. Putnam, Professor E. C. Goldsworthy acted as secretary.

$$
\begin{aligned}
& \text { T. M. Putnam, } \\
& \text { Associate Secretary }
\end{aligned}
$$

